V.K. CHETTY

Medical College of Wisconsin

Milwaukee, Wisconsin

DILIP RATHA

The World Bank

Washington, D.C.

\title{
On Finite Life Times and Growth
}

Following Diamond (1965), most authors assume that "capital argument of the production function is the saving of the previous period," but ignore this lag in determining the capital price. In an overlapping generations model with production lags, growth is feasible if capital productivity is sufficiently high and borrowing is for capital services. If labor services must also be financed, that is, if wages should be paid in advance, then steady growth is infeasible, if capital is fully owned by the old. Our results highlight the crucial role played by time-structure of production in the determination of growth process.

\section{Introduction}

The search for possibilities of sustained growth in an overlapping generations (OLG) model with convex production has led to a consistently negative result, of which Jones and Manuelli (1992) present an elegant proof to the effect that the asymptotic growth rate in one-sector models of this type is bounded above by zero. The intuition is that as the economy embarks on a sustained growth path, the income of the young savers fails to grow as fast as the capital stock so that eventually the young cannot purchase the large capital stock. Simply put, sustained growth is not possible because saving falls short of the required investment. For positive growth to be possible, therefore, it is necessary to either increase saving or reduce the investment demand. This is demonstrated by Jones and Manuelli (JM) with the help of three examples; their first example involves a direct transfer of income from the old (non-savers) to the young; the next example introduces a second sector comprised of capital that cannot be directly consumed and is produced only with capital, and therefore, has the effect of restraining consumption and promoting saving; while their third example explicitly introduces increasing returns to capital so that as the growth process progresses, not only saving increases, the investment demand also falls.

The crucial factor behind the no-growth result is the inability to finance investment. The need for and the amount of financing depends upon the time-structure of the production process. If, for example, production is instantaneous, there is absolutely no need for financing. The purpose of the 


\section{V.K. Chetty and Dilip Ratha}

present note is to study the relation between production structure and growth. We consider two cases: (i) a one-sector model where production involves current labor input but capital with one-period lag, and (ii) where production requires both capital and labor to be input one period ahead. It is seen that in both cases, the investment required to maintain a steady non-negative growth (including zero growth or the stationary state) is likely to exceed available saving.

Our results complement the JM result and bring out the importance of the time-structure in a production economy. They also complement the finding of Aiyagari (1987) that, in an OLG model without production, a monetary steady state does not exist when the consumer's discount rate is greater than the population growth rate. The introduction of a production process that involves lags (and hence an asset for lending and borrowing) leads to non-existence of steady states irrespective of the relationship between the discount rate and the population growth rate.

We derive these results in the next section.

\section{Time Structure of Production}

Consider an OLG economy where the representative agent lives for two periods, supplies inelastically one unit of labor in the first period and consumes in the second period all his income from the saving of the previous period. The representative individual born at time $t$ solves

$$
\operatorname{Max} u^{t}\left(c^{t}, c_{t+1}^{t}\right)
$$

subject to

$$
\begin{gathered}
c_{t}^{t}+s_{t} \leq w_{t}, \\
c_{t+1}^{t} \leq s_{t}\left(1+r_{t+1}\right), \\
\left(c_{t}^{t}, c_{t+1}^{t}\right) \geq 0,
\end{gathered}
$$

where $c, s, w$ and $r$ are respectively consumption, saving, wage rate and the interest rate.

There is only one good which can be consumed or invested. The production of output $Y$ involves capital $K$ and labor $N$, that is, $Y_{t}=F\left(K_{t-1}, N_{t}\right) .^{1}$ We consider two time-structures: (i) output is produced using current labor, but material input (for example, seed capital) has to be applied one year

${ }^{1}$ The authors would like to acknowledge a referee for pointing out the redundancy of assumptions on $F$ in an earlier draft. 
before, and (ii) production requires both labor and materials to be applied one year ahead.

Case I. $Y_{t}=F\left(K_{t-1}, N_{t}\right)$.

Since production takes time, the representative firm has to finance investment by borrowing. Let $B_{t}$ be the stock of one period bonds supplied in period $t$ with a rate of interest $r_{t+1}$. The firm then faces the following intertemporal constraint on the flow of funds:

$$
B_{t-1}\left(1+r_{t}\right)+N_{t} w_{t}+K_{t}=Y_{t}+B_{t} .
$$

The l.h.s. of this equation shows total outlay consisting of loan repayment and investment while the r.h.s. shows total receipts. Any maximization problem for the firm must satisfy this flow constraint.

Zero profit condition requires that

$$
B_{t-1}\left(1+r_{t}\right)+N_{t} w_{t}=Y_{t}
$$

which together with (1) implies $B_{t}=K_{t}$ and, we get

$$
K_{t-1}\left(1+r_{t}\right)+N_{t} w_{t}=Y_{t}
$$

A steady state is an equilibrium where relative prices remain constant over time and all other variables grow at a rate $\mathrm{n}$, the growth rate of population (in other words, the per capita magnitudes remain constant over time). A stationary state is a steady state with $n=0$.

We will now prove the following result:

When $Y_{t}=F\left(K_{t-1}, N_{t}\right)$, a steady state is feasible only if the capital-labor substitutability is such that the capital-output ratio $\beta=K_{t-I} Y_{t}$ is not greater than $1 /(2+n+r)$.

Equation (2) can be written as

$$
Y_{t}=\beta Y_{t}(1+r)+N_{t} w
$$

or

$$
Y_{t}=N_{t} w /[1-\beta(1+r)] .
$$

This implies that $K_{t}=(1+n) K_{t-1}=(1+n) \beta Y_{t}=(1+n) \beta N_{t} w /[1$ $-\beta(1+r)]$. Since $B_{t}=K_{t}$, we have

$$
B_{t} / N_{t}=[w(1+n) \beta] /[1-\beta(1+r)] .
$$

The term in brackets in the r.h.s. will be greater than 1 if $\beta>1 /(2$ $+n+r)$. The per capita ${ }^{2}$ bond demand will then exceed wages, and therefore saving, rendering steady-state equilibrium growth infeasible.

${ }^{2}$ We will use "per capita" and "per young worker" interchangeably for convenience. 


\section{V.K. Chetty and Dilip Ratha}

Several interesting implications follow from this condition $\beta>1 /(2$ $+n+r)$. First, steady growth may be possible if the average productivity of capital $1 / \beta$ is sufficiently high to start with. Thus, as demonstrated by Solow (1956), substitution possibilities will help to reduce the amount of loan and hence help to prove the existence of a steady state. On the other hand, even a stationary state $(n=0)$ may not be feasible unless initial conditions are characterized by sufficiently high capital productivity (recall that the JM result does not rule out the possibility of a stationary state).

Our proposition that the steady state with positive growth rate is possible when $\beta \leq 1 / 2+n+r$, if the production function is the type $Y_{t}$ $=F\left(K_{t-1}, N_{t}\right)$ seems to contradict the $\mathrm{JM}$ result that the steady state with positive growth is impossible if the production function is the type $Y_{t}$ $=F\left(K_{t}, N_{t}\right)$.

In OLG models, the production function is written as $Y_{t}=F\left(K_{t}, N_{t}\right)$, indicating no time lag between the application of inputs and the availability of output. Following Diamond (1965), all authors also assume that "capital argument of the production function is the saving of the previous period plus the capital stock employed in the previous period" (net of depreciation) and write $s_{t}=K_{t+1}$ (Jones and Manueli 1990, 176; Diamond 1965, 1127, 1132; Blanchard and Fischer 1989, 94). Hence, $Y_{t}=F\left(s_{t-1}, N_{t}\right)$ and there is lag in production. And the price of capital is the value of one unit of consumption good saved in the previous period, which is $(1+r)$, and not 1 . However, in the literature, the price of capital is always assumed to be one.

JM also demonstrate that growth is feasible, if the price of capital is different from one and if the capital productivity is sufficiently high. It is clear that growth or no growth depends crucially on the determination of the factor prices, in particular the price of capital, and the definition of income.

Case II. $Y_{t}=F\left(K_{t-1}, N_{t-1}\right)$.

Using the same arguments as in the previous section, we get

$$
Y_{t}=F\left(K_{t-1}, N_{t-1}\right)=\left(K_{t-1}+N_{t-1} w_{t-1}\right)\left(1+r_{t}\right) .
$$

Using this in (1), we have

$$
B_{t}-B_{t-1}\left(1+r_{t}\right)=K_{t}-K_{t-1}\left(1+r_{t}\right)+\left(N_{t} w_{t}-N_{t-1} w_{t-1}\right)\left(1+r_{t}\right),
$$

which in a steady state yields

$$
B_{t}=K_{t}+N_{t} w_{t}
$$

that is,

$$
B_{t} / N_{t}>w_{t}
$$


since $K_{t} / N_{t} />0$. Thus, per capita bond demand is now unconditionally greater than wage and available saving, ruling out steady state (as well as stationary state).

This result clearly brings out the importance of the time structure of production in the determination of sustained growth. Note that the only difference between this case and the earlier case is that producers now borrow for wages as well as material inputs. Intuitively, when the loan is for material inputs (for example, seed corn), it can be repaid in the next period, if the productivity (of corn) is sufficiently high. When the loan is to finance the wage bill (which grows at an exogenous rate) on top of material inputs, obviously the loan would have to be higher than the wages, at least in the initial period. In a steady state, however, the per capita borrowing as well as wage rate must remain constant over time, so the inequality between per capita bonds and wages carries over to all periods. Capital-labor substitution will not help in this case, since labor also requires (working) capital. As Wicksell remarked long ago,

\begin{abstract}
Walras calls "capital" and treats as "capital" only durable goods, but not raw materials and half-finished products and not the means of subsistence of workers... It is therefore implicitly assumed by Walras that workers and other producers maintain themselves during production and receive remuneration for their productive services from the proceeds of the product in question only after the completion of the production. . . . A necessary consequence of this is the peculiar fact that these equations of production and exchange can give no information at all about the level of the rate of interest $(1893,167)$.
\end{abstract}

These inconsistency results extend easily to two-sector models where the second sector comprises of an intermediate capital (not directly consumable), as long as the production process involves lags (see Chetty 1990; Chetty and Ratha 1991).

Received: January 1995

Final version: July 1995

\title{
References
}

Aiyagari, S. Rao. "Optimality and Monetary Equilibria in Stationary Overlapping Generations Models with Long-Lived Agents: Growth Versus Discounting." Journal of Economic Theory 43 (1987): 292-313.

Blanchard, Olivier, and Stanley Fischer. Lectures on Macroeconomics. Cambridge: The MIT Press, 1989.

Diamond, P.A. "National Debt in a Neo-Classical Growth Model." American Economic Review 55, no. 5 (1965): 1126-50. 


\section{V.K. Chetty and Dilip Ratha}

Chetty, V.K. "Debt, Taxes and Output in a Model with Fixed Capital." Discussion Paper, Department of Economics, Oakland University, Rochester, Michigan, 1990.

Chetty, V.K., and Dilip Ratha. "Rationality, Capital Accumulation and Steady States." Discussion Paper, Department of Economics, Oakland University, Rochester, Michigan, 1991.

Jones, Larry E., and Rodolfo E. Manuelli. "A Convex Model of Equilibrium Growth." Journal of Political Economy 98 (1990):1008-38.

-. "Finite Lifetimes and Growth." Journal of Economic Theory 58 (1992):171-97.

Solow, Robert M. "A Contribution to the Theory of Economic Growth." Quarterly Journal of Economics 70 (1956): 65-94.

Wicksell, K. Value Rent and Capital. London: George Allen \& Unwin, 1893. 